\title{
Computed Tomography Assisted-Detection of Occult Elbow Fractures in adult Patients with Positive Elbow Extension Test
}

\author{
MOHAMMED A.A. BATAT, M.Sc.*; WEAM F. MOUSA, M.D.**; MAHMOUD A. EL-ROSASY, M.D.** and \\ MOHAMMED A. ROMEIH, M.D.** \\ The Departments of Emergency Medicine \& Traumatology* and Orthopedic Surgery**, Faculty of Medicine, \\ Tanta University, Tanta, Egypt
}

\begin{abstract}
Background: Elbow fractures are a common injury seen among Emergency Department trauma patients accounting for $2-3 \%$ of Emergency Department attendances. Eight to ten percent of fractures in adults occur in the elbow and forearm an effective clinical decision rule to exclude fracture in acute elbow injury would prevent unnecessary radiography, and could reduce missed injuries. Previous small studies indicate that the ability to fully extend the elbow might rule out clinically significant bony injury.
\end{abstract}

Aim of the Work: The aim of this work was to detect occult adult elbow fractures using computed tomography in adult patients who presented with positive elbow extension test and had no evident fracture on X-ray study.

This was to test the effectiveness of positive elbow extension test as an indication to perform further radiographic evaluation of the injured elbow.

Material and Methods: A prospective study was conducted in the Emergency Department (ED) of Tanta University Hospitals. All patients underwent the standard procedures of the protocol.

Our study was carried out upon forty (40) patient of both sex in a duration of one (1) year from October 2016 to October 2017. They were selected from those who presented to Tanta University, Emergency Department.

Results: In this study, age of about $57.5 \%$ of patients were ranged 19-39 years. While only about 5\% of patients were equal or more than 60 years old.

In patients with $\mathrm{CT}$ show elbow fracture, mean age was 38.27, while in patients had no elbow fracture mean age was 36.89. There was no statistically significant difference between patients.

The most commonly occult elbow fracture detected by $\mathrm{CT}$ in patient with positive elbow extension test was radial head fracture $(22.5 \%$ of all studied patients).

About $20 \%$ of patients was diagnosed as coronoid process fracture, $5 \%$ of patients was diagnosed as olecranon process

Correspondence to: Dr. Mohammed A.A. Batat, E-Mail: mohammedbatat1388@gmail.com fracture and $5 \%$ of patients was diagnosed as lateral epicondyle fracture. Only about $2.5 \%$ of patients was diagnosed as medial epicondyle fracture.

Conclusions: In patients with positive elbow extension test adding computed tomography to plain radiograph (that showed no evident fracture) was found to be superior to plain $\mathrm{X}$-ray alone.

Key Words: Occult elbow fractures - Elbow extension test Computed tomography.

\section{Introduction}

DESPITE its high frequency, there is no standardized method of diagnosis using conventional Xray imaging for trauma patients presenting with elbow pain and restricted elbow movement, signs of haemoarthrosis, and direct or indirect signs of fracture on plain X-ray imaging studies. such as an anterior or posterior fat pad signs, might be absent [1].

Only a minority of patients with such injuries have a fracture, but although clinical decision rules for other limb injuries are recognized, no guidelines have been established to indicate which patients with an elbow injury require radiography [2].

An effective clinical decision rule to exclude fracture in acute elbow injury would prevent unnecessary radiography, and could reduce missed injuries. Previous small studies indicate that the ability to fully extend the elbow might rule out clinically significant bony injury [3]

The elbow extension test is an examination that measures the ability to fully extend the elbow while sitting down or standing and with shoulders at 90 degrees in flexion. The test is considered positive and elbow injury is suspected when the patient is unable to fully extend his/her elbow [4]. 
The elbow extension test has therefore been proposed as a simple means of excluding the need for a radiograph, but has yet to be validated in routine practice and has not been well studied in children [5]

Clinical decision rules for other limb injuries are widely accepted and resulted in less radiography and reduced waiting times. We aim to identify clinical signs that can be used to predict the need for radiography in elbow injury [6] .

This test can easily be practiced in the emergency can be used as a sensitive clinical screening test for patients with acute injury to the elbow. Patients who can fully extend the affected elbow can be safely treated without radiography [7] .

However, management of trauma patients who have a limitation of elbow movement and normal $\mathrm{X}$-ray imaging is still uncertain.

\section{Patients and Methods}

Study design:

A prospective study was conducted in the Emergency Department (ED) of Tanta University Hospitals. All patients underwent the standard procedures of the protocol.

Ethics of the study:

The Research Ethical Committee, Faculty of Medicine, Tanta University approved the design of the study. An informed written consent was obtained from all patients or from the relatives after full explanation of benefits and risks.

Privacy of all patient data was granted and there was code number for every patient file that includes all investigations.

\section{Study population:}

Our study was carried out upon forty (40) patient of both sex in a duration of one (1) year from October 2016 to October 2017. They were selected from those who presented to Tanta University, Emergency Department.

Methods of the study:

All patients were subjected to:

I- Full history taking from the patient or his/her relatives:

- Personal history: This included the age, and sex.

- Medical history: This included hypertension, diabetes mellitus.
- Neurological history: This included history of neuromuscular disease.

- History of special habits.

\section{II- Mechanism of injury:}

In the case of a traumatic event, the mechanism of injury helps guide the diagnosis. For traumatic injuries, specific symptoms can be highly useful in determining a diagnosis.

- Direct elbow trauma.

- Indirect trauma: e.g. falling on outstretched hand.

III- Complain of the patient.

IV- Clinical examination.

A- General examination:

- Vital signs: This included blood pressure, heart rate, temperature, respiratory rate, saturation of oxygen by pulse oximetry $\left(\mathrm{SpO}_{2}\right)$.

- Neurological examination.

- Cardiovascular examination.

- Chest examination.

- Abdominal examination.

- Examination of extremities.

B- Local examination of the Elbow:

- Inspection: (From front, side, and behind).

- Presence of abrasion, lacerations, contusion or contusion.

- Presence of ecchymosis, erythema near the elbow.

- Swelling: Diffuse or local swelling.

- Palpation: Included.

- Point of tenderness.

- Palpation of olecranon, medial, and lateral epicondyle.

- Assessment of peripheral pulsation.

- Assessment of sensations.

- Assessment of motor function:

1- Patients were assessed for active elbow joint movement including:

A- Elbow flexion: Normal range of motion from $0-145^{\circ}$.

B- Elbow extension: Normal range of motion $0^{\circ}$

C- Pronation: Patients were asked to have their elbows by their sides, and flexed at $90^{\circ}$ (normal range of motion $0-85^{\circ}$ ). 
D- Supination: Normal range of motion $0-90^{\circ}$.

2- Patients were assessed for passive elbow joint for crepitus.

- Elbow extension test.

\section{Principle of test:}

With the trochlea of the distal humerus inserting into the trochlear notch of the ulna, with full elbow extension a hard end feel occurs. This position is the close-packed position of the elbow. With the presence of a fracture, full extension was blocked.

Test position: Standing position.
Steps of the test: Fig. (1):

- Patients were allowed to stand.

- Then, arms were exposed and supinated.

- Patients were asked to flex their shoulders to $90^{\circ}$.

- After that, patients were asked to fully extend and lock both elbows.

- Injured and uninjured sides were compared visually for reaching full extension of the elbow.

- Patients with unequal extension were recorded, and included in our study (positive elbow extension test).
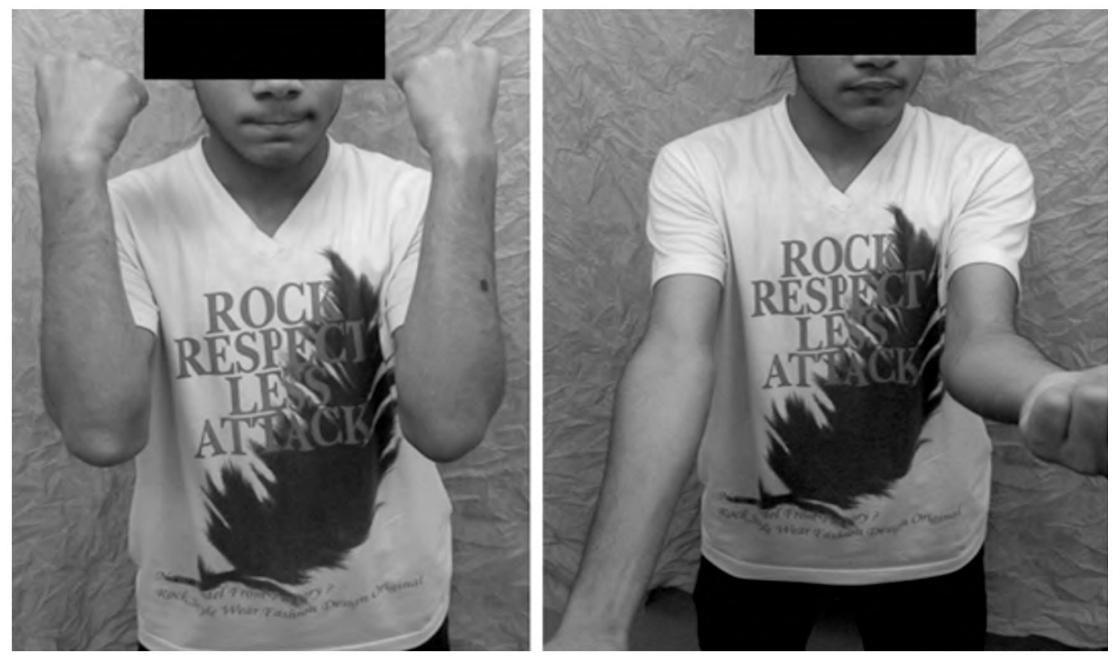

Fig. (1): Steps of the test.

\section{Statistical analysis:}

In this study, data were organized and tabulated. SPSS Version 19 (Statistical Package for Social Studies) created by IBM, Illinois, Chicago, USA was used to statistically analyze the collected data. The level of significant was adopted at $p<0.05$.

\section{Results}

In this study, age of about $57.5 \%$ of patients were ranged $19-39$ years. While only about $5 \%$ of patients were equal or more than 60 years old.

About $55 \%$ of our patients were male, while female patients represented about $45 \%$ of patients included in this study.

In our study, the most commonly occult elbow fracture detected by CT in patient with positive elbow extension test was radial head fracture ( $22.5 \%$ of all studied patients).

About $20 \%$ of patients was diagnosed as coronoid process fracture, $5 \%$ of patients was diagnosed as olecranon process fracture and $5 \%$ of patients was diagnosed as lateral epicondyle fracture. Only about $2.5 \%$ of patients was diagnosed as medial epicondyle fracture.

Table (1): Age distribution of patients.

\begin{tabular}{lcc}
\hline Age (years) (37.65 11.99) & \multicolumn{2}{c}{ Patients with Elbow Trauma } \\
\cline { 2 - 3 } Range (19-62) & $\mathrm{N}=40$ & $\%$ \\
\hline $19-39$ & 23 & 57.5 \\
$40-59$ & 15 & 37.5 \\
\hline
\end{tabular}

Table (2): Comparison of age in years for patients with and without elbow fracture.

\begin{tabular}{lcc}
\hline Age (years) & $\begin{array}{c}\text { Patients with CT } \\
\text { show elbow fracture } \\
(\mathrm{n}=22)\end{array}$ & $\begin{array}{c}\text { Patients with CT } \\
\text { show no elbow fracture } \\
(\mathrm{n}=18)\end{array}$ \\
\hline Mean $\pm \mathrm{SD}$ & $38.27 \pm 11.39$ & $36.89 \pm 12.98$ \\
$t$-test & & 0.359 \\
$p$-value & & 0.722 \\
\hline
\end{tabular}


Table (3): Sex distribution of patients.

\begin{tabular}{lcc}
\hline \multirow{2}{*}{ Sex } & \multicolumn{2}{c}{ Patients with Elbow Trauma } \\
\cline { 2 - 3 } & $\mathrm{N}=40$ & $\%$ \\
\hline Male & 22 & 55 \\
Female & 18 & 45 \\
\hline Total & 40 & 100 \\
\hline
\end{tabular}

Table (4): Comparison of sex for patients with elbow fracture and with no elbow fracture.

\begin{tabular}{|c|c|c|}
\hline Sex & $\begin{array}{c}\text { Patients with CT } \\
\text { show elbow fracture } \\
{[\mathrm{n}(\%)]}\end{array}$ & $\begin{array}{c}\text { Patients with CT } \\
\text { show no elbow fracture } \\
{[\mathrm{n}(\%)]}\end{array}$ \\
\hline Male & $13(59.1)$ & $9(50)$ \\
\hline Female & $9(40.9)$ & $9(50)$ \\
\hline Total & $22(100)$ & $18(100)$ \\
\hline$\chi^{2}$ & & 0.331 \\
\hline$p$-value & & 0.565 \\
\hline
\end{tabular}

Table (5): Comparison of medical history for patients with elbow fracture and with no elbow fracture.

\begin{tabular}{lccc}
\hline Medical history & $\begin{array}{c}\text { Patients with } \\
\text { CT show elbow } \\
\text { fracture } \\
{[\mathrm{n}(\%)]}\end{array}$ & $\begin{array}{c}\text { Patients with } \\
\text { CT show no } \\
\text { elbow fracture } \\
{[\mathrm{n}(\%)]}\end{array}$ & Total \\
\hline No co-morbidities & $15(68.2)$ & $13(72.2)$ & 28 \\
HTN & $3(13.6)$ & $3(16.7)$ & 3 \\
DM & $2(9.1)$ & $2(11.1)$ & 4 \\
HTN and DM & $2(9.1)$ & 18 & 40 \\
Total & 22 & 2.973 & \\
$\chi^{2}$ & \multicolumn{3}{c}{0.396} \\
$p$-value & \multicolumn{3}{|l}{} \\
\hline
\end{tabular}

Table (6): Comparison of mode of trauma for patients with elbow fracture and with no elbow fracture.

\begin{tabular}{|c|c|c|}
\hline Mode of trauma & $\begin{array}{l}\text { Patients with CT } \\
\text { show elbow } \\
\text { fracture }[\mathrm{n}(\%)]\end{array}$ & $\begin{array}{l}\text { Patients with CT } \\
\text { show no elbow } \\
\text { fracture [n (\%)] }\end{array}$ \\
\hline Direct trauma & $9(40.9)$ & $11(61.1)$ \\
\hline Indirect trauma & $13(59.1)$ & $7(38.9)$ \\
\hline Total & $22(100)$ & $18(100)$ \\
\hline$x^{2}$ & \multicolumn{2}{|c|}{1.616} \\
\hline$p$-value & \multicolumn{2}{|c|}{0.204} \\
\hline
\end{tabular}

Table (7): Comparison of vital signs for patients with elbow fracture and with no elbow fracture.

\begin{tabular}{lcccc}
\hline $\begin{array}{l}\text { Vital } \\
\text { signs }\end{array}$ & $\begin{array}{c}\text { Patients with } \\
\text { CThow elbow } \\
\text { fracture } \\
(\mathrm{n}=22)\end{array}$ & $\begin{array}{c}\text { Patients with } \\
\text { CT show no } \\
\text { elbow fracture } \\
(\mathrm{n}=18)\end{array}$ & $\begin{array}{c}t \text { - } \\
\text { test }\end{array}$ & $\begin{array}{c}p \text { - } \\
\text { value }\end{array}$ \\
\hline MBP & $93.18 \pm 10.51$ & $90.5 \pm 9.41$ & 0.841 & 0.406 \\
Pulse & $82.68 \pm 6.19$ & $81.28 \pm 6.66$ & 0.690 & 0.494 \\
RR & $18.77 \pm 1.54$ & $18.83 \pm 1.47$ & 0.126 & 0.900 \\
\hline
\end{tabular}

Table (8): Finding of CT elbow in studied patients.

\begin{tabular}{lll}
\hline CT elbow & $\mathrm{N}$ & $\%$ \\
\hline No Evidence of fracture & 18 & 45.0 \\
Radial head fracture & 9 & 22.5 \\
Coronoid process fracture & 8 & 20.0 \\
Olecranon process fracture & 2 & 5.0 \\
Lateral epicondyle fracture & 2 & 5.0 \\
Medial epicondyle fracture & 1 & 2.5 \\
\hline Total & 40 & 100 \\
\hline
\end{tabular}

\section{Discussion}

The range of age in our study was from 19 to 62 years with a mean age 37.65 years. There was no statistically significant difference between patient show elbow fractures and patients with no evident of elbow fracture in computed tomography (CT).

Also in Amiri H, et al., [8] study who asked about role preserved active range of motion to exclude the need of radiography in patients with elbow trauma. It was carried out on 102 patients with a mean age $32.2 \pm 21.6$ (range from 5-87) years.

In addition, Appelboam A, et al., [9] study that studied the role of elbow extension test to exclude elbow fractures. It screened 2127 patients over 21 months (960 adults and 780 children). The age range of the adults was $16-94$ with a mean 38 years.

In a study by Major NM, et al., [10] who evaluated the role of Magnetic Resonance Imaging (MRI) in detecting occult fracture in patients with elbow trauma. The age of all patients exposed to the study ranged from 4 to 80 years old.

\section{I- Gender:}

In our study regarding gender, there was no statistically significant difference between patient show elbow fractures and patients with no evident of elbow fracture in Computed Tomography (CT). About $55 \%$ of patients in this study were male, while female represented about $45 \%$ of patients.

Our study was in concordance with Amiri H, et al., [8] study that showed that about $66.7 \%$ of patients were males.

In line with this study, Appelboam, et al., [9] study showed about $51 \%$ of patients were males with no statistically significant difference in gender.

\section{Mode of trauma:}

Concerning mode of trauma, we tried to cover direct isolated elbow trauma and indirect or twisting 
elbow injuries in our study. In patients with, and without elbow fracture, about $40.9 \%$, and $61.1 \%$ of respectively were subjected to direct elbow trauma with no significant difference between both groups.

In Acar, et al., [11] study that studied utility of $\mathrm{CT}$ in elbow trauma patient. The studied patients were 39 patients, $82.1 \%$ of these patients (32) had a direct trauma mechanism (fall from heights), and about $92.3 \%$ of patients (36) had isolated elbow trauma.

\section{Finding of CT elbow:}

In our study, the main type of fracture would be missed in patient with normal X-ray and positive elbow extension test was radial head fracture which was diagnosed with aid of CT (represented about $22.5 \%$ of all studied patients). While coronoid process, olecranon process, lateral condyle, and medial condyle fracture represented about 20,5, $5,2.5 \%$ of patients, respectively. The remaining $45 \%$ of patients had a positive elbow extension test, normal X-ray, and normal CT study.

Acar, et al., [11] study mentioned that with aid of CT study in patient with normal plain X-ray and positive extension test radius fracture humerous fracture represented about $10.6 \%$, In our study, the main type of fracture would be missed in patient with normal X-ray and positive elbow extension test was radial head fracture which was diagnosed with aid of CT (represented about $22.5 \%$ of all studied patients).

\section{Sensitivity of elbow extension test:}

The main result in our study is that elbow extension test sensitivity is $100 \%$ positive test in all patient included in our study and add positive predictive value was 55 .

Lamprakis, et al., [12] study that evaluated the elbow extension test to be used as alternative to radiograph was highly relevant to our results according to their survey results, the elbow extension test reached a high sensitivity also in concordance with other published reports supporting our results.

A rather interesting study by Lennon RI, et al., [13] concluded that emergent elbow radiographs are not required in patients with normal extension supination and flexion.

Docherty, et al., [14] study that evaluate the role of elbow extension as a test of clinical significant injury was in line with our study, and reported a sensitivity of $97.3 \%$, and a specificity of 69.4 .

\section{Limitation of the study:}

- Study sample was conducted upon 40 patients that was too small to clear our target in necessity of elbow extension test.

- Our study was mainly upon adult patients above age of 18 years old while large number of patients with elbow trauma affect younger age group.

- Common obstacle to face us in our study is the financial part that limit examining all patient with computed tomography.

\section{Conclusions:}

Elbow extension test has a moderate predictive value $55 \%$ in detection of occult elbow fractures especially when done by non-orthopedic personnel even with the aid of computed tomography.

In patients with positive elbow extension test adding computed tomography to plain radiograph (that showed no evident fracture) was found to be superior to plain X-ray alone.

In patients with positive elbow extension test plain radiography is an essential preliminary examination.

If an elbow fracture could not be confirmed computed tomography is the next imaging of choice.

\section{Recommendations:}

Computed tomography should be used as another imaging tool of choice for patients presented to the emergency department after acute elbow trauma with positive elbow extension test and plain $\mathrm{X}$-ray study show no evident fracture. It was associated with increased percentage of sensitivity to detect elbow fractures.

More studies are needed to confirm sensitivity of elbow extension test together with computed tomography not to miss present elbow fracture.

To be preferred that elbow extension test done by trained emergency physican as this give this test more accuracy more than when done by primary care personnel.

\section{References}

1- DARRACQ M., VINSON D. and PANACEK E.: Preservation of Active Range of Motion after Acute Elbow Trauma Predicts Absence of Elbow Fracture. The American Journal of Emergency Medicine, 26 (7): 779-82, 2008.

2- O'DRISCOLL S., JUPITER J., COHEN M., et al.: Difficult Elbow Fractures: Pearls and Pitfalls. Instructional Course Lectures, 52: 113-34, 2003. 
3- McGINLEY J., ROACH N., HOPGOOD B., et al.: Non displaced Elbow Fractures: A Commonly Occurring and Difficult Diagnosis. The American Journal of Emergency Medicine, 24 (5): 560-6, 2006.

4- JOSHI N., LIRA A., MEHTA N., et al.: Diagnostic Accuracy of History, Physical Examination, and Bedside Ultrasound for Diagnosis of Extremity Fractures in the Emergency Department: A Systematic Review. Academic Emergency Medicine, 20 (1): 1-5, 2013.

5- MACKWAY-JONES K.: The Rational Clinical Examination in Emergency Care. British Medical Journal, 337 (5): a2374-6, 2008 .

6- JIE K., VAN DAM L. and HAMMACHER E.: Isolated Fat Pad Sign in Acute Elbow Injury: Is It Clinically Relevant? European Journal of Emergency Medicine, 23 (3): 228-31, 2016.

7- JIE K., VAN DAM L., VERHAGEN T., et al.: Extension Test and Ossal Point Tenderness Cannot Accurately Exclude Significant Injury in Acute Elbow Trauma. Annals of Emergency Medicine, 64 (1): 74-8, 2014.

8- AMIRI H., VAHDATI S., FEKRI S., et al.: Does Preservation of Active Range of Motion after Acute Elbow Injury Rule Out the Need for Radiography? Ulus Travma Acil. Cerrahi. Derg., 18 (6): 479-82, 2012.
9- APPELBOAM A., REUBEN A., BENGER J., et al.: Elbow Extension Test to Rule Out Elbow Fracture: Multicentre, Prospective Validation and Observational Study of Diagnostic Accuracy in Adults and Children. British Medical Journal, 338 (7685): 31-5, 2009.

10- MAJOR N. and CRAWFORD S.: Elbow Effusions in Trauma in Adults and Children: Is There an Occult Fracture? American Journal of Roentgenology, 178 (2): 413 8, 2002.

11-ACAR K., AKSAY E., ORAY D., et al.: Utility of Computed Tomography in Elbow Trauma Patients with Norma $X$-Ray Study and Positive Elbow Extension Test. The Journal of Emergency Medicine, 50 (3): 444-8, 2016.

12- LAMPRAKIS A., VLASIS K., SIAMPOU E., et al.: Can Elbow-Extension Test Be Used as an Alternative to Radiographs in Primary Care? The European Journal of General Practice, 13 (4): 221-4, 2007.

13- LENNON R., RIYAT M., HILLIAM R., et al.: Can a Normal Range of Elbow Movement Predict a Normal Elbow X-Ray? Emergency Medicine Journal, 24 (2): 868, 2007.

14-DOCHERTY M., SCHWAB R. and JOHN O.: Can Elbow Extension Be Used as a Test of Clinically Significant Injury? Southern Medical Journal, 95 (5): 539-42, 2002.

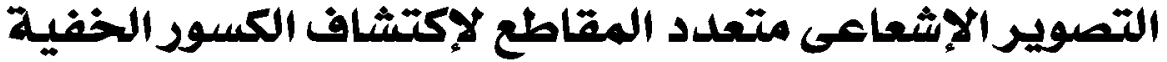

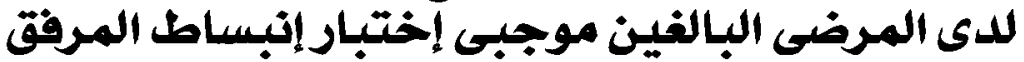

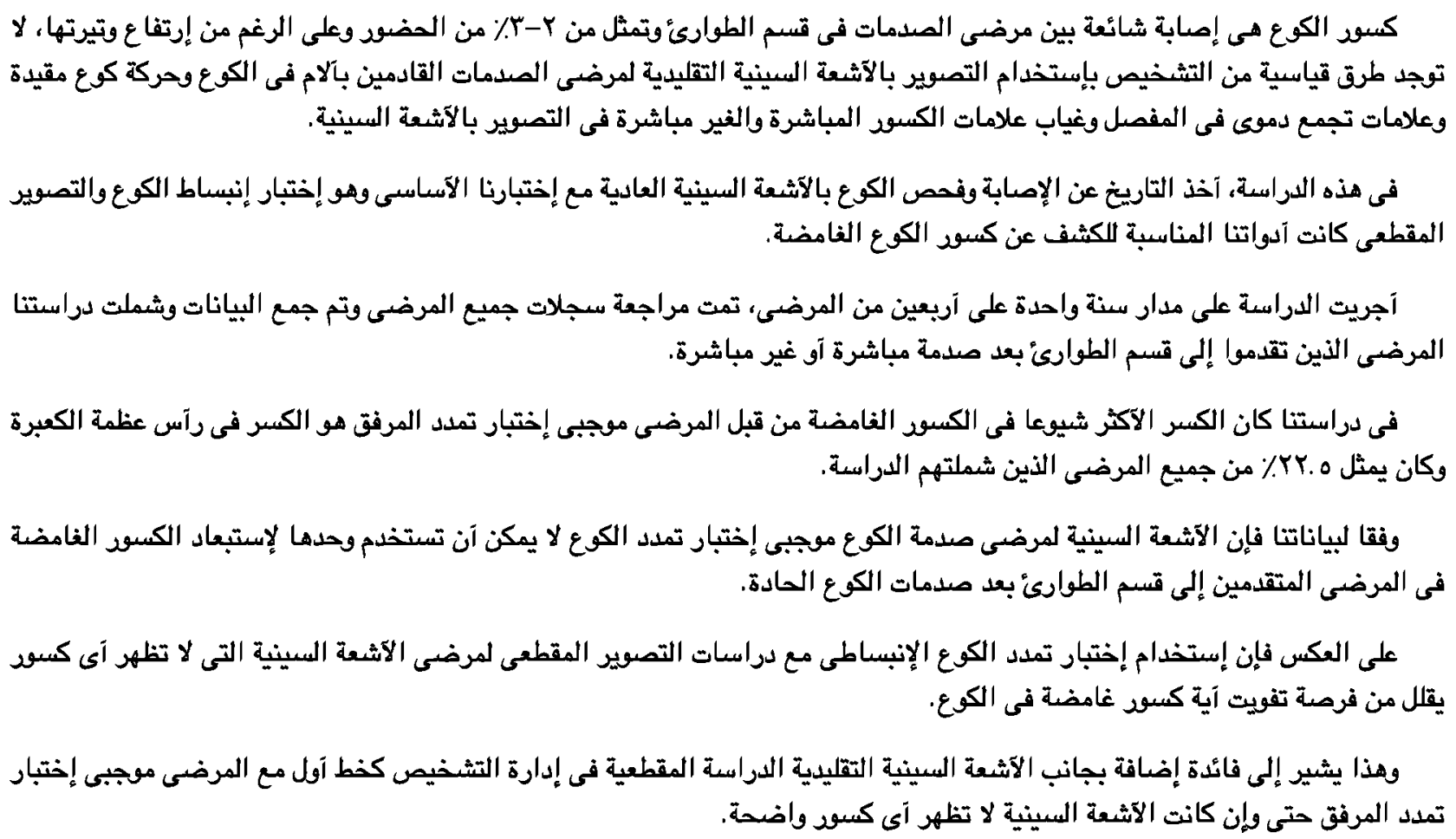

